\title{
SMALL BOWEL GIST: CASE REPORTS AND REVIEW OF LITERATURE
}

\section{J. Abirami Krithiga ${ }^{1}$, S. Jeyakumar², R. Jaivinod Kumar³, Tharun ${ }^{4}$}

\section{HOW TO CITE THIS ARTICLE:}

J. Abirami Krithiga, S. Jeyakumar, R. Jaivinod Kumar, Tharun C. "Small Bowel GIST: Case Reports and Review of Literature". Journal of Evolution of Medical and Dental Sciences 2014; Vol. 3, Issue 48, September 29;

Page: 11601-11607, DOI: 10.14260/jemds/2014/3520

ABSTRACT: GIST may present as an abdominal mass, obstruction, haemorrhage in the gastrointestinal tract or perforation. Literature on perforated jejunal GIST is scarce. Here by, reporting 2 cases of jejunal GIST. Perforated jejunal GIST in an elderly lady, who presented with mass abdomen. En-bloc resection of the tumor giving a clear margin was done. Immunohistochemistry showed a GIST of aggressive behavior and a case jejunal GIST in a young patient who presented with pain in abdomen. Resection of the jejunal segment containing mass and end to end anastomosis done. Immunohistochemistry showed intermediate type. Both the patients are undergoing adjuvant therapy with imatinib mesylate. A comprehensive review on GIST is being attempted.

KEYWORDS: gastrointestinal stromal tumor, perforated jejunal GIST, Small bowel GIST.

INTRODUCTION: BACKGROUND: The gastrointestinal stromal tumor (GIST) is the most common sarcoma of the gastrointestinal (GI) tract. It accounts for $0.2 \%$ of the gastro intestinal tumors. The stomach is the commonest site followed by small bowel, rectum and the esophagus. It may remain asymptomatic and may only be detected incidentally. Literature gives very few examples of a perforated small bowel GIST. Here, we discuss a case which presented as an abdominal mass and was found to be a jejunal GIST with perforation.

\section{CASE PRESENTATION:}

CASE 1: A seventy three year old lady presented with lower abdominal pain for the past one year. She gave history of weight loss and decreased appetite. She was on regular treatment for systemic hypertension. On physical examination she was poorly nourished and had a tender intra-abdominal mass of 10x7 cm occupying right iliac, lumbar and umbilical region with restricted mobility. Other system examinations were normal.

Contrast enhanced CT abdomen showed a well-defined large lobulated circumferential exophytic wall thickening of small bowel with multiple areas of necrosis and calcification without luminal narrowing. It also showed severe adhesions to surrounding structures.

Fig. 1: CECT shows well defined large lobulated circumferential exophytic wall thickening of small bowel with multiple areas of necrosis and calcification without luminal narrowing

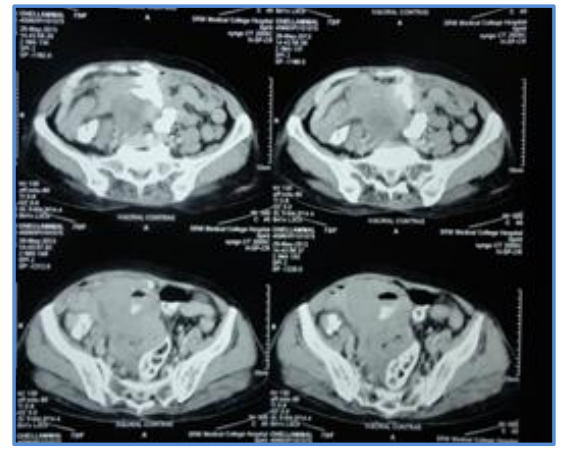

Fig. 1 


\section{CASE REPORT}

CT screening of chest was normal. Colonoscopy revealed extraneous compression over the recto-sigmoid and upper GI endoscopy was normal.

Fig. 2: A 12x $10 \mathrm{~cm}$ mass in the ante mesenteric border of the jejunum

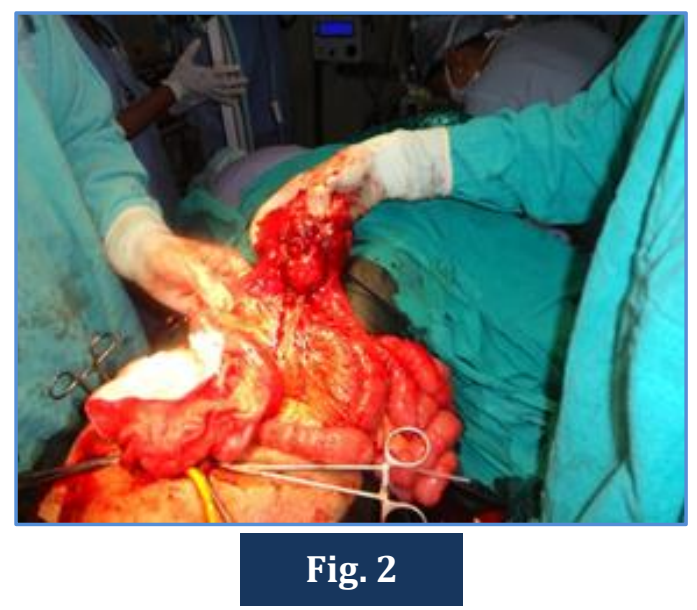

Explorative laparotomy was done through a lower midline incision. A 12x $10 \mathrm{~cm}$ mass in the ante mesenteric border of the jejunum with severe adhesions to jejunal mesentery, laterally to peritoneal folds and gonadal vessels, inferiorly to pelvic peritoneum and roof of bladder and anteriorly to rectus and recto-sigmoid.

Right ureter was pushed to the opposite side. Adhesions were released and the tumor was resected en-bloc along with a part of the jejunum. Tumor was adherent to the wall of the bladder and was opened during dissection. End to end anastomosis of jejunum done and bladder closed in layers over a supra pubic catheter. Postoperatively, she had hypoalbuminemia and electrolyte imbalances, which were tackled appropriately.

Fig. 3: The resected tumor along with a part of the jejunum

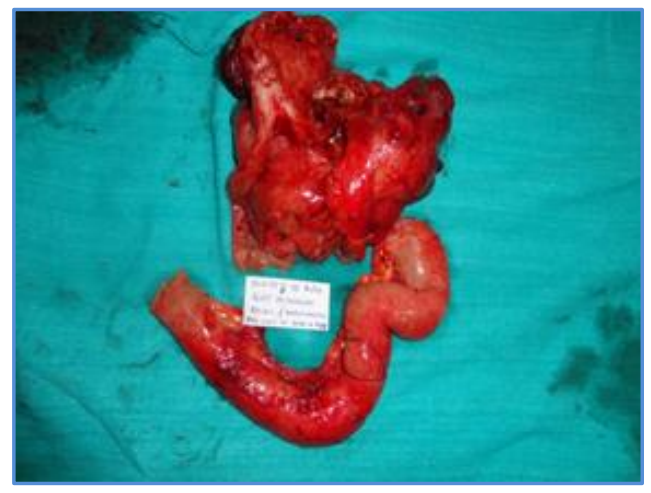

\section{Fig. 3}

Cut section showed focal areas of cystic and hemorrhagic changes and an area of mucosa was found to be perforated and contained by the tumor surrounding it. Histopathological examination was suggestive of a high grade GIST (G2 tumor) of mixed cell type with high mitotic rate $\left(12 / 5 \mathrm{~mm}^{2}\right)$ 


\section{CASE REPORT}

and areas of necrosis and the margins were clear of tumor cells. Immunohistochemistry showed vimentin, CD34, c-KIT positivity which was consistent with GIST of aggressive behavior.

The patient was started on imatinib mesylate $400 \mathrm{mg}$ daily and is on regular follow up.

CASE 2: A twenty nine year old lady presented with lower abdominal pain for the past 4 months. She gave history decreased appetite. No comorbid illness. On physical examination she was thin built and had tenderness in lower abdomen. Other system examinations were normal.

USG abdomen showed a well-defined isoechoic lesion in left adenexal region. Both ovaries not separately visualized from lesion, possibility of subserosal fibroid or ovarian lesion. Contrast enhanced CT abdomen showed a hypodense lesion measuring $44 \times 42 \mathrm{~mm}$ on the left side of uterus with in homogenous enhancement, possibility of ovarian mass.

Fig. 4: CECT showing hypo dense lesion measuring $44 \times 42 \mathrm{~mm}$ on the left side of uterus with inhomogeneous enhancement, possibility of ovarian mass.

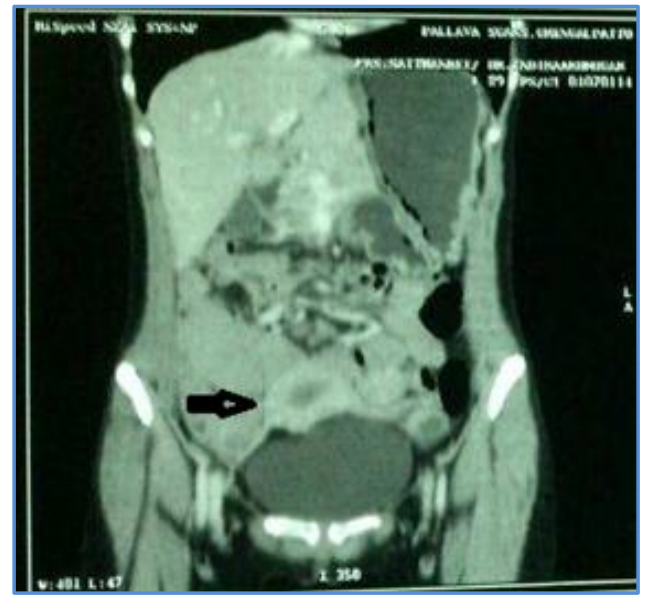

\section{Fig. 4}

Diagnostic laparoscopy was done. A stalked polypoidal mass of size arising from the jejunum was found.

Fig. 5: Laparoscopic view of the solid tumor from antemesentric border of jejunum

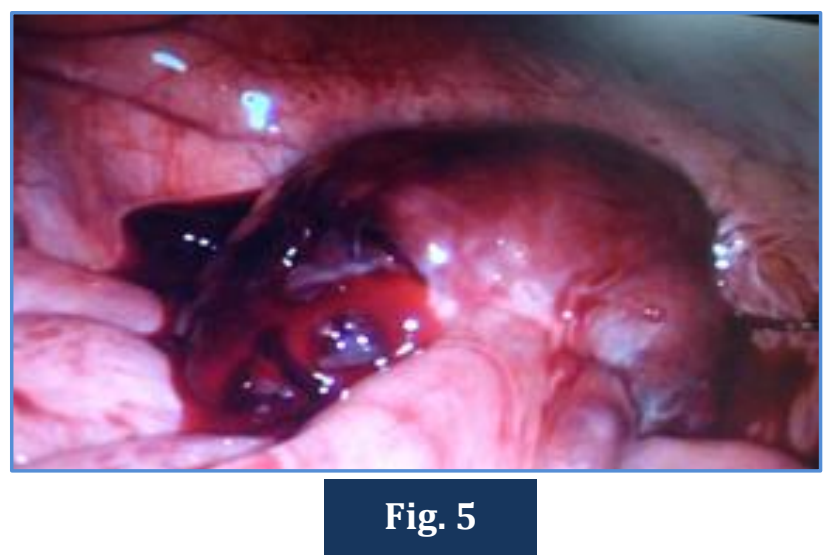


Explorative laparotomy was done through a midline incision. A $6 \times 5 \times 4 \mathrm{~cm}$ polypoidal mass in the ante mesenteric border of the jejunum. Polyp attached to intestine by a short stalk measuring $0.5 \mathrm{~cm}$ in length. Resection of jejunum containing GIST and end to end anastomosis of jejunum done.

Fig. 6: Cut section showed focal areas of solid and myxoid changes.

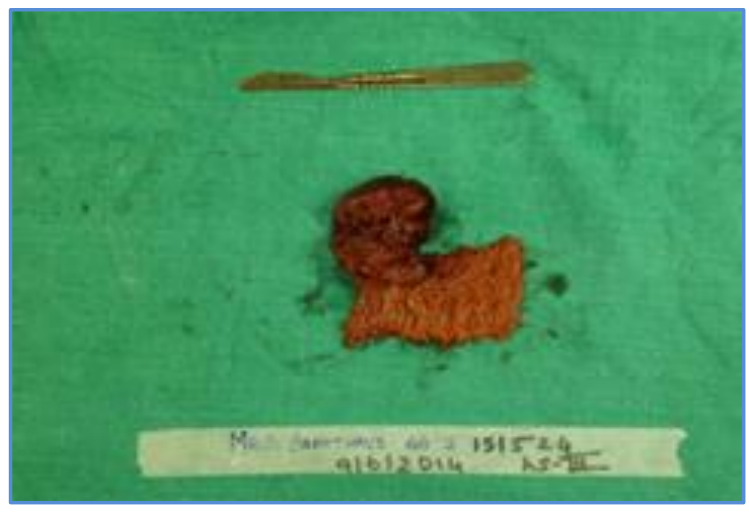

Fig. 6

Cut section showed focal areas of solid and myxoid changes. Histopathological examination was suggestive of GIST of spindle cell type with mitosis $(<5 / 50 \mathrm{HPF})$ and the margins were clear of tumor cells. Immunohistochemistry showed CD34, CD1117 positivity. The patient was started on imatinib mesylate and is on regular follow up.

DISCUSSION: The expression of c-KIT (CD117) distinguishes GIST from other gastrointestinal smooth muscle tumors. The initial ambiguity in its distinction from a leiomyoma or a leiomyosarcoma due to the phenotypic overlap has now tailed off. It was first described by Mazur and Clark in 1983.

The Surveillance, Epidemiology, and End Results (SEER) registry reports an incidence of 0.32 in 100,000 population per year, and a prevalence of 1.62 per 100,00 per year during a 15-year period [1]. The tumor shows $20-30 \%$ malignant potential.[2] It occurs in the stomach (60\%), jejunum and ileum (30\%), duodenum (5\%), colo-rectum (4\%), and esophagus or appendix (1\%).[3-9] It rarely presents as extra-gastrointestinal GIST in mesentery, omentum and retroperitoneum. ${ }^{[10]}$

These mesenchyme tumors are thought to originate from the interstitial cells of Cajal or related stem cell like precursors.[11] Though the exact pathogenesis remains unclear, Hirota et al.(1998) pointed to the gain of function mutation in c-KIT[12] and Heinrich et al towards mutations in in platelet-derived growth factor receptor $\alpha$ (PDGFRA).[13] Recent studies have shown a germ line mutations in succinate dehydrogenase (SDH), leading to complete loss of SDH protein.[14,15]

It is more common in adults above the age of 40 years with a slight male preponderance.[16] Seventy percent are symptomatic at presentation, $20 \%$ are asymptomatic and $10 \%$ are detected at autopsy.[17,8] Clinical presentations include abdominal mass (5-50\%), obstruction (5\%), haemorrhage and rarely perforation (0.8\%).[19,20] Abdominal pain, loss of weight and appetite and anemia are also common features.

Owing to the lack of specific signs or symptoms, a preoperative diagnosis of GIST is grueling. Contrast enhanced CT scan is the preferred imaging modality in patients presenting with an 
abdominal mass. However, endoscopic ultrasound and fine needle aspiration is diagnostic in 89\% cases.[21-23] Most common metastatic sites are liver and peritoneum and less commonly, the lungs. Lymphatic spread is rare.[24]

The treatment modality is primarily surgical, ensuring the complete removal of the tumor with involved neighboring structures giving a clear surgical margin. Roy et al[26] suggests the use of distilled water for peritoneal lavage after surgery as it has a cytolytic activity on the tumor cells and hence prevent peritoneal spillage. The discovery of tyrosine kinase receptor mutations in the pathogenesis has led to the usage of tyrosine kinase inhibitor, imatinib mesylate as an adjuvant to surgery and in inoperable and recurrent cases.[25]

Sunitinib has been in use since 2006 for imatinib resistant GIST. Response of the tumor to conventional chemotherapy is poor.[26] The most common histologic subtype is the spindle cell variety. Others include epithelioid type and mixed spindle and epithelioid type.[27,28] Though there appears to be no correlation between the tumor size and the mitotic index and neither of them to the histological subtype, the former two factors are used in risk stratification and evaluating prognosis.[27] Complete surgical resection gives a chance of 48-65\% five-year survival.[19] However, perforation of the tumor drops the five-year survival to $24 \%$, probably due to peritoneal dissemination.[17]

Large size, increased mitotic activity and location of the tumor in the small bowel are associated with poor prognosis. Positron Emission Tomography (PET) is a very good tool for postoperative follow up of patients on imatinib.[26] The median survival period is 9 to 16 months in case of recurrence.

The c-KIT expression, which is pathognomonic of GIST, can be negative in 5\% of the cases.[29] A recently detected marker, DOG1 (Discovered on GIST 1), a calcium-activated chloride channel is found to be highly expressed in GIST, with an overall sensitivity of 75-100\%.

CONCLUSION: There are only 15 cases of perforated jejunal GIST reported in literature so far.[26] Our case was peculiar in that, the perforation was contained by the tumor itself. With the large size, location in jejunum, high mitotic index, advanced age of the patient and dense adhesions to surrounding structure, the prognosis of our case needs to be watched. Nevertheless, this case stands out for its rarity of presentation and anatomical location.

\section{REFERENCES:}

1. Rubin JL, Sanon M, Taylor DC, et al. Epidemiology, survival, and costs of localized gastrointestinal stromal tumors. Int J Gen Med. 2011; 4: 121-30.

2. Hiremath P B, Bansal N, Meenal C, Thulasiraman VN, Kumar ASP, Hiremath R. A Rare case of GIST presented as leiomyoma. Int J Med Res Health Sci.2013; 2(2): 317-320.

3. Miettinen M, Furlong M, Sarlomo-Rikala M, et al. Gastrointestinal stromal tumors, intramural leiomyoma's, and leiomyosarcomas in the rectum and anus: a clinic pathologic, immune his to chemical, and molecular genetic study of 144 cases. Am J Surg Pathol. 2001; 25(9): 1121-33.

4. Miettinen M, Kopczynski J, Makhlouf HR, et al. Gastrointestinal stromal tumors, intramural leiomyomas, and leiomyosarcomas in the duodenum: a clinic pathologic, immune his to chemical, and molecular genetic study of 167 cases. Am J Surg Pathol. 2003; 27(5): 625-41. 
5. Miettinen M, Makhlouf H, Sobin LH, et al. Gastrointestinal stromal tumors of the jejunum and ileum: a clinic pathologic, immune his to chemical, and molecular genetic study of 906 cases before imatinib with long-term follow-up. Am J Surg Pathol. 2006; 30(4): 477-89.

6. Miettinen M, Sarlomo-Rikala M, Sobin LH, et al. Esophageal stromal tumors: a clinic pathologic, immune histochemical, and molecular genetic study of 17 cases and comparison with esophageal leiomyomas and leiomyosarcomas. Am J Surg Pathol. 2000; 24(2): 211-22.

7. Miettinen M, Sobin LH. Gastrointestinal stromal tumors in the appendix: a clinic pathologic and immune his to chemical study of four cases. Am J Surg Pathol. 2001; 25(11): 1433-7.

8. Miettinen M, Sobin LH, Lasota J. Gastrointestinal stromal tumors of the stomach: a clinic pathologic, immune his to chemical, and molecular genetic study of 1765 cases with long-term follow-up. Am J Surg Pathol. 2005; 29(1): 52-68.

9. Trupiano JK, Stewart RE, Misick C, et al. Gastric stromal tumors: a clinic pathologic study of 77 cases with correlation of features with nonaggressive and aggressive clinical behaviors. Am J Surg Pathol. 2002; 26 (6): 705-14.

10. Miettinen M, Lasota J. Gastrointestinal stromal tumors: pathology and prognosis at different sites. Semin Diagn Pathol. 2006; 23 (2): 70-83.

11. Kindblom LG, Remotti HE, Aldenborg F, Meis-Kindblom JM. Gastrointestinal pacemaker cell tumor (GIPACT): gastro in test in al stromal tumors show phenotypic characteristics of the interstitial cells of Cajal. Am J Pathol 1998, 152 ((5)): 1259-1269.

12. Hirota S, Isozaki K, Moriyama $\mathrm{Y}$, et al. Gain-of-function mutations of c-kit in human gastrointestinal stromal tumors. Science. 1998; 279(5350): 577-80.

13. Heinrich MC, Corless CL, Demetri GD, et al. Kinase mutations and imatinib response in patients with metastatic gastrointestinal stromal tumor. J Clin Oncol. 2003; 21(23): 4342-9.

14. Janeway KA, Liegl B, Harlow A, et al. Pediatric KIT wild-type and platelet-derived growth factor receptor alpha-wild-type gastrointestinal stromal tumors share KIT activation but not mechanisms of genetic progression with adult gastrointestinal stromal tumors. Cancer Res. 2007; 67(19): 9084-8.

15. Janeway KA, Kim SY, Lodish M, et al. Defects in succinate dehydrogenase in gastrointestinal stromal tumors lacking KIT and PDGFRA mutations. Proc Natl Acad Sci U S A. 2011; 108(1): 314-8.

16. Sornmayura P. Gastrointestinal stromal tumors (GISTs): a pathology view point. J Med Assoc Thai 2009, 92: 124-135.

17. Steigen SE, Bjerkehagen B, Haugland HK, Nordrum IS, Løberg EM, Isaksen V, Eide TJ, Nielsen TO. Diagnostic and prognostic markers for gastrointestinal stromal tumors in Norway. Mod Pathol 2008, 21: 46-53.

18. Wilson SL, Wheeler WE. Giant leiomyoma of the small intestine with free perforation into the peritoneal cavity. South Med J 1992, 85: 667-668.

19. Efremidou EI, Liratzopoulos N,Papageorgiou MS, Romanidis K. Perforated GIST of the small intestine as a rare cause of acute abdomen: surgical treatment and adjuvant therapy. Case report. J Gastrointestin Liver Dis 2006, 15: 297-99.

20. Oida Y, Motojuku M, Morikawa G, Mukai M, Shimizu K, Imaizumi T, Makuuchi H. Laparoscopicassisted resection of gastrointestinal stromal tumor in small intestine. Hepatogastroenterology 2008, 55: 146-49. 


\section{CASE REPORT}

21. Huang CC, Yang CY, Lai IR, Chen CN, Lee PH, Lin MT. Gastrointestinal stromal tumor of the small intestine: a clinic pathologic study of 70 cases in the post imatinib era. World J Surg 2009, 33: 828-834.

22. Kingham TP, De Matteo RP. Multidisciplinary treatment of gastrointestinal stromal tumors. Surg Clin North Am 2009, 89: 217-233.

23. Annaberdyev S, Gibbons J, Hardacre JM. Dramatic response of a gastrointestinal stromal tumor to neoadjuvant imatinib therapy. World J Surg Oncol 2009, 7: 30.

24. De Matteo RP, Lewis JJ, Leung D, et al. Two hundred gastrointestinal stromal tumors: recurrence patterns and prognostic factors for survival. Ann Surg. 2000; 231(1): 51-58.

25. Foo W C, Atzwanger BL, Lazar AJ. Pathology of Gastrointestinal Stromal Tumors. Clinical Medicine Insights: Pathology 2012: 5.

26. Roy SD, Khan D, De KK, De U. Spontaneous perforation of jejunal gastrointestinal stromal tumour (gist). Case report and review of literature. World Journal of Emergency Surgery 2012, $7: 37$.

27. Miettinen M, Lasota J. Gastrointestinal stromal tumors: review on morphology, molecular pathology, prognosis, and differential diagnosis. Arch Pathol Lab Med 2006, 130 (10): 14661478.

28. Fletcher CD, Berman JJ, Corless $\mathrm{C}$, et al. Diagnosis of gastrointestinal stromal tumors: a consensus approach. Hum Pathol.2002; 33 (5): 459-465.

29. Patil DT, Rubin BP. Gastrointestinal Stromal Tumor- Advances in Diagnosis and Management. Arch Pathol Lab Med-Vol 135, October 2011.

\section{AUTHORS:}

1. J. Abirami Krithiga

2. S. Jeyakumar

3. R. Jaivinod Kumar

4. Tharun C.

\section{PARTICULARS OF CONTRIBUTORS:}

1. $3^{\text {rd }}$ Year Resident, Department of General Surgery, SRM Medical College \& Hospital.

2. Professor, Department of General Surgery, SRM Medical College \& Hospital.

3. Associate Professor, Department of General Surgery, SRM Medical College \& Hospital.

4. Assistant Professor, Department of General

NAME ADDRESS EMAIL ID OF THE CORRESPONDING AUTHOR:

Dr. J. Abirami Krithiga,

Room No. 609,

SRM Medical College PG Girls Hostel, SRM Medical College \& Hospital,

Potheri, Chennai - 603203

Email: abishivi_jaks@yahoo.com

Date of Submission: 11/09/2014.

Date of Peer Review: 12/09/2014.

Date of Acceptance: 19/09/2014.

Date of Publishing: 29/09/2014. 